\title{
Persistence of intrathecal oligoclonal B cells and IgG in multiple sclerosis
}

Alina Tomescu-Baciua, ${ }^{a, 1}$ Jorunn N. Johansen ${ }^{a, 1}$, Trygve Holmøy ${ }^{b, c}$, Victor Greiffa,c, Maria Stensland ${ }^{\mathrm{a}, \mathrm{d}}$, Gustavo Antonio de Souza ${ }^{\mathrm{a}, \mathrm{d}, 2}$, Frode Vartdal ${ }^{\mathrm{a}}$, and Andreas Lossius ${ }^{\mathrm{b}, \mathrm{a},{ }^{*}}$

aDepartment of Immunology and Transfusion Medicine, Faculty of Medicine, University of Oslo and Oslo University Hospital Rikshospitalet, Oslo, Norway

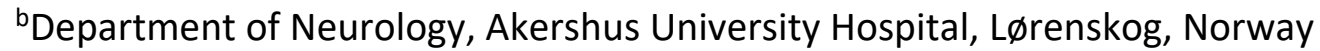
Institute of Clinical Medicine, Faculty of Medicine, University of Oslo, Oslo, Norway dProteomics Core Facility, Oslo University Hospital Rikshospitalet, NO-0372 Oslo, Norway

${ }^{1}$ The authors contributed equally to this study.

2Present address: Department of Biochemistry, Federal University of Rio Grande do Norte, RN 59056-450 Natal, Brazil

*Corresponding author: Andreas Lossius, Department of Immunology and Transfusion Medicine, Oslo University Hospital Rikshospitalet, Postboks 4950 Nydalen, N-0424 Oslo, Norway. Phone: +47.2307.3814. Fax: +47.2307.3510. E-mail address:

andreas.lossius@medisin.uio.no

Abbreviations: CSF, cerebrospinal fluid; EDSS, expanded disability status scale; IGHV, immunoglobulin heavy-chain variable; IPG, immobilized pH gradient; OCBs, oligoclonal bands 


\section{Abstract}

In multiple sclerosis (MS), B cells are trafficking across the blood-brain barrier, but it is not known how this relates to the synthesis of oligoclonal IgG. We used quantitative mass spectrometry of oligoclonal bands and high-throughput sequencing of immunoglobulin heavy-chain variable transcripts to study the longitudinal B cell response in the cerebrospinal fluid (CSF) and blood of two MS patients. Twenty of 22 (91\%) and 25 of 28 (89\%) of oligoclonal band peptides persisted in samples collected 18 months apart, in spite of a dynamic exchange across the blood-CSF barrier of B lineage cells connecting to oligoclonal $\lg$.

Keywords: Multiple sclerosis; cerebrospinal fluid; B cells; oligoclonal bands 


\section{Introduction}

Intrathecal synthesis of immunoglobulin $\mathrm{G}(\operatorname{IgG})$ was demonstrated in multiple sclerosis (MS) for more than half a century ago (Kabat et al., 1948). This locally produced IgG is a diagnostic hallmark of MS, and it can be visualized by isoelectric focusing as oligoclonal bands (OCBs) in $90 \%$ of patients (Dobson et al., 2013). The presence of OCBs may be associated with a worse prognosis (Joseph et al., 2009), and it has a high predictive value for conversion from clinically isolated syndrome to clinical definite MS (Dobson, Ramagopalan, 2013, Tintore et al., 2008). Consequently, in the most recent diagnostic criteria of relapsing-remitting MS, the presence of OCBs may substitute for dissemination in time (Thompson et al., 2018).

It has been shown that OCB IgG match a proportion B cell IgG transcripts from the cerebrospinal fluid (CSF) and brain (Obermeier et al., 2011, Obermeier et al., 2008), suggesting that OCB IgG is produced by $B$ lineage cells within these compartments. In more recent studies, we and others have shown that B lineage cells participating in the local immune response have clonally related counterparts in blood and cervical lymph nodes (Johansen et al., 2015, Stern et al., 2014, von Budingen et al., 2012), indicating an exchange of B lineage cells between the periphery and the CNS. In support of this view, it has been demonstrated that OCB IgG can be traced to B cells in blood (Bankoti et al., 2014). Moreover, antibody-secreting B lineage cells in the CSF express high levels of the proliferation marker Ki-67 and have a phenotype compatible with recently activated shortlived plasmablasts (Cepok et al., 2005, Lossius et al., 2017). Accordingly, blocking lymphocyte migration to CNS with natalizumab has been shown to make OCBs disappear in around half of patients (Mancuso et al., 2014), supporting the idea that the intrathecal humoral immune 
response is sustained by a continuous support of B cells from the periphery, at least in a proportion of patients.

The data above indicate a dynamic humoral immune response in MS, connecting $B$ lineage cells in blood and cervical lymph nodes to B lineage cells and OCBs in the CNS. However, earlier studies that compared OCB patterns on electrophoretic gels showed a relatively stable pattern over time (Axelsson et al., 2013, Walsh and Tourtellotte, 1986). Thus, to establish whether oligoclonal IgG persists and how it relates to B lineage cells in the CSF and blood, we here use high-throughput sequencing of transcribed immunoglobulin heavy chain variable (IGHV) genes and mass spectrometry of OCB IgG in two MS patients. 


\section{Materials and methods}

\subsection{Patients}

Two patients with relapsing-remitting MS, fulfilling the 2010 revisions of McDonalds criteria (Polman et al., 2011), were recruited at Akershus University Hospital (Lørenskog, Norway). The study was approved by the Regional Ethical Committee of the South-Eastern Norwegian Health Authority (2009/23 S-04143a), and the patients gave written informed consent before inclusion. Their age and disease characteristics, as well as the CSF parameters at inclusion and repuncture, are provided in Table 1.

\subsection{Sample preparation and high-throughput sequencing}

We collected between 20 and $25 \mathrm{ml} \mathrm{CSF}$ by lumbar puncture and approximately $60 \mathrm{ml}$ blood by venipuncture at each time point. Mononuclear cells were isolated, and samples were prepared as previously described (Johansen, Vartdal, 2015). Multiplex PCR of IGHV cDNA and high-throughput sequencing on the Illumina MiSeq system were performed by Adaptive Biotechnologies (USA) using the immunoSEQ survey level assay (coverage $\leq 100,000$ B cells) (Larimore et al., 2012). The survey level depth was chosen for both CSF and blood mononuclear cells in order to make valid comparisons across the two compartments. The sequencing raw data were preprocessed and normalized as previously described (Johansen, Vartdal, 2015).

\subsection{Isoelectric focusing and mass spectrometry}

We purified IgG from $3 \mathrm{ml}$ of CSF and an equivalent amount of IgG from serum using Protein G Dynabeads (Thermo Fisher Scientific, USA). After eluting the IgG in urea-based rehydration buffer as described (Obermeier, Mentele, 2008), we rehydrated the immobilized pH-gradient 
(IPG) strips (Immobiline DryStrips $24 \mathrm{~cm}$; GE Healthcare, USA) for $18 \mathrm{~h}$ and performed isoelectric focusing of paired CSF and serum IgG using Ettan IPGphor (Amersham Biosciences, UK). The voltage was increased in consecutive steps up to $8000 \mathrm{~V}$ as recommended by the manufacturer, and the total focusing time was $15 \mathrm{~h}$ and $30 \mathrm{~min}$. The IPG strips were immediately fixated and stained using a sensitive coomassie-based protocol (Dyballa and Metzger, 2009). Visible oligoclonal bands were excised and swelled in $50 \mu \mathrm{l}$ of $10 \mathrm{mM}$ DTT in $50 \mathrm{mM} \mathrm{NH} 4 \mathrm{HCO} 3$ and incubated for $20 \mathrm{~min}$ at $56^{\circ} \mathrm{C}$. After removal of excess liquid, the pieces were alkylated in $50 \mu \mathrm{l}$ of $55 \mathrm{mM}$ iodoacetamide in $0.1 \mathrm{M} \mathrm{NH}_{4} \mathrm{HCO}_{3}$ for 30 min at room temperature protected from light. After washing the pieces in Milli-Q water, they were dried using a SpeedVac Vacuum Consentrator and rehydrated in $25 \mu \mathrm{l}$ of ice cold $0.025 \mu \mathrm{g} / \mu \mathrm{l}$ trypsin solution $\left(1 \mu \mathrm{l} 0.5 \mu \mathrm{g} / \mu \mathrm{l}\right.$ trypsin in $\left.99 \mu \mathrm{l} 50 \mathrm{mM} \mathrm{NH}_{4} \mathrm{HCO}_{3}\right)$. The pieces were incubated on ice at $45 \mathrm{~min}$ and left overnight at $37^{\circ} \mathrm{C}$. The analyses were performed in duplicates on a QExactive hybrid quadrupole-Orbitrap mass spectrometer equipped with Easy nLC1000 nano-LC system (all from Thermo Fisher Scientific).

\subsection{Data analysis}

The transcriptomic data were analyzed using the ImmunoSeq Analyzer 3.0 (Adaptive Biotechnologies) and IMGT/HighV-QUEST 1.6.5 (Alamyar et al., 2012). CDR3 clustering was performed within the $\mathrm{R}$ statistical programming environment using the $\mathrm{R}$ package stringdist (https://cran.r-project.org/web/packages/stringdist/citation.html) as previously described (Greiff et al., 2017). CDR3s were clustered by identical V-gene, J-gene, CDR3 length, and a maximal edit distance of 1 (denoted non-redundant sequences) (Greiff et al., 2015). Lineage trees were constructed from these data using IgTree (Barak et al., 2008) and Cytoscape v.

3.7.0. The mass spectrometry data were filtered for CDR3-region hits (denoted CDR3 
peptides) using PEAKS Studio v. 6, and the CDR3 peptides were quantified using MaxQuant software (Cox and Mann, 2008). Graphs were created using GraphPad Prism v. 8. 


\section{Results}

\subsection{Clusters of IgG B lineage cells persist in the CSF}

We sequenced IGHV transcripts of IgG B lineage cells from CSF and blood from two MS patients at two time points (Table 1). The time span between the sample collections was 18 months for both patients. None of the patients had received any immunomodulatory drugs at the initial inclusion. Before the second sample collection, MS-1 received treatment with natalizumab the first 12 months, whereas MS-2 received interferon beta-1a. None of them had evidence of disease activity (clinical or MRI) at sample collections, but MS-2 had experienced two sensory attacks between the two time points. The number of unique IGHV transcripts acquired from CSF and blood at the two time points are given in Table 2.

We observed that several IGHV transcripts were related, indicating common ancestor B lineage cells undergoing somatic hypermutation and proliferation. With this in mind, all transcripts were translated to amino acid sequences and clustered based on an identical CDR3 length, the same $\mathrm{V}$ - and J-gene usage, and a similar CDR3 sequence, allowing an edit distance of 1 between related CDR3 sequences (Table 2). The overlap of unique CSF IGHV transcripts between the two time points was $70 / 676(10 \%)$ for MS-1 and $86 / 853(10 \%)$ for MS-2 (Fig. 1A). Focusing on clustered non-redundant amino acid sequences, the overlap between the CSF repertoires at the two time points were $37 / 353(10 \%)$ and $24 / 177(14 \%)$, respectively (Fig. 1A). Next, we used the clusters of related sequences to construct lineage trees comprising IGHV transcripts detected at one or both time points in CSF and/or blood (representative lineage trees are shown in Fig. 1B). Interestingly, the lineage trees generally included several IGHV transcripts detected at both time points, but most related transcripts 
were detected at one of the time points only. These observations indicate the persistence of identical and related IgG B lineage cells in the CSF of the MS patients investigated.

\subsection{Oligoclonal IgG persists in the CSF}

In order to extend our analyses to intrathecally synthesized IgG, we performed isoelectric focusing of paired serum and CSF from both time points, excised visible OCBs (Fig. 3A and 4A), and performed label-free quantitative mass spectrometry. A summary of CDR3 peptides detected in all OCBs are given in Table 3. Our approach yielded a total of 22 CDR3 peptides matching IGHV transcripts from the CSF of MS1 and 28 CDR3 peptides matching IGHV transcripts from the CSF of MS2. Remarkably, 20 of 22 (91\%) and 25 of 28 (89\%) of these OCB peptides were detected at both time points (Table 2), and the relative peptide abundances at the two time points based on LC-MS peak intensities quantified in MaxQuant were within the same range (Fig. 2). These results show a strong qualitative and quantitative persistence of oligoclonal IgG in the CSF of the two MS patients.

\subsection{Clusters of B lineage cells producing oligoclonal IgG persist in the CSF}

Finally, we restricted our analysis to persistent OCB peptides that had matching IGHV transcripts at both time points (i.e. a persistence of both IgG and matching IGHV transcripts). We detected 6 such CDR3 peptides matching IGHV transcripts within 2 clusters for MS1, and 6 CDR3 peptides matching IGHV transcripts within 4 clusters for MS2 (Table 3), which all involved IGHV transcripts of the IGHV4 family that were the members of lineage trees that were also extending to blood (Fig. 3B and Fig. 4B). In several instances, we detected OCB peptides matching differently mutated members within the same lineage trees, confirming the existence of these related B lineage cells also at the protein level. Strikingly, label-free 
quantitation of these peptides showed a similar abundance in the exact same, or in neighboring OCBs, at the two time points (Fig. 3A and B; Fig. 4A and B). Taken together, our data demonstrate persistence of both CSF B lineage cells and matching OCB peptides in both patients investigated. 


\section{Discussion}

To investigate the intrathecal humoral immune response in MS at different time points at both the transcriptomic and proteomic level, we here combined high-throughput sequencing of IGHV transcripts with quantitative mass-spectrometry of OCB IgG. The results demonstrate an intrathecal persistence of several clusters of related OCB IgG-producing CSF B lineage cells that were also related to $B$ lineage cells in blood. Nonetheless, the majority of the B cell clones were detected at only one time point, whereas matching OCB IgG in most cases were present in equal amounts at both time points. This is consistent with a highly stable humoral immune response in the CSF of MS patients and underscores that finite samples of CSF cells only represent a small proportion of the IgG-producing B lineage cells in the CNS. The results corroborate early observations of stable OCB patterns on electrophoretic gels (Walsh and Tourtellotte, 1986), and shed new light on previous and contemporary studies detecting a limited overlap in B lineage cell samples collected at different time points (Colombo et al., 2003, Greenfield et al., 2019).

Related IgG B lineage cells populate the parenchyma, the meninges, and the CSF in MS (Lovato et al., 2011, Obermeier, Lovato, 2011), and OCBs probably represent the products of a limited number of antibody-secreting cells within these populations. Thus, a finite sample of CSF B lineage cells may miss relevant IgG-secreting cells and include irrelevant bystander B cells. This is in line with previous data from our group demonstrating similar, but not identical, OCB patterns of in vivo and in vitro IgG synthesis (Skorstad et al., 2009). However, it is also possible that the turnover of B lineage cells is greater in the CSF than in the parenchyma and meninges, and that the dynamics we observe in the CSF B cell repertoire are not always translated into other compartments. Accordingly, IgG-producing cells in the 
CSF are highly proliferating plasmablasts (Lossius, Tomescu-Baciu, 2017), and at least some isotype-switched B lineage cells in the CSF continue to express activation-induced cytidine deaminase, the enzyme involved in somatic hypermutation (Beltran et al., 2014).

It has been shown that two years of natalizumab therapy induces a complete or partial disappearance of OCBs in a majority of MS patients (Mancuso, Franciotta, 2014). Although one of the patients in our study (MS-1) had received natalizumab for the first 12 months between sample collections, we detected a strong persistence of OCB IgG. The duration of natalizumab therapy is probably relevant for the effect on the intrathecal immune response, and 12 months might not be long enough to attain an enduring suppression of the OCB synthesis. Nevertheless, it is unknown why some patients continue to display OCBs despite long-term treatment, and it could be speculated that these patients have a greater proportion of long-lived plasma cells lingering within survival niches in the CNS.

A study has shown that a proportion of antibodies expressed by CSF B cells recognize neuronal nuclei and/or astrocytes (Ligocki et al., 2015). This has been confirmed in an independent study also demonstrating that recombinant CSF IgG produces demyelination in spinal cord explant cultures (Blauth et al., 2015). However, the exact antigens recognized by these sets of antibodies remain unknown. Curiously, another study that was able to pinpoint the specificity of three recombinant CSF IgG antibodies from two MS patients, found that they targeted ubiquitous intracellular proteins, supporting the idea that the intrathecal humoral immune response might be a secondary reaction to tissue injury (Brandle et al., 2016). Nonetheless, the strong persistence of the humoral repertoire as demonstrated here, together with the previously shown biased usage of the IGHV4 gene family (Johansen, 
Vartdal, 2015, Owens et al., 2007, von Budingen, Kuo, 2012), and the patterns of somatic mutations in particular codons of the IGHV4 family genes (Cameron et al., 2009, Rounds et al., 2015), argue for a non-random activation of B lineage cells that are targeting shared epitopes and/or an idiotope-driven immune response (Hoglund et al., 2017).

There are several methodological limitations to this study. Firstly, since we did not sequence the $5^{\prime}$-end of the IGHV transcripts, we were unable to detect somatic mutations in this region. Secondly, we made cDNA from mononuclear cells using a primer specifically mapping to the IGHG gene without knowledge of the true frequency of IgG-expressing B cells. This was done to maximize the coverage of B cell transcripts from low CSF cell numbers but precluded a true estimation of the repertoire coverage in the samples. This approach also limited our analysis to antigen-experienced B lineage cells of the IgG isotype. Further, we did not analyze sorted B cell populations, which could have provided information on the overlap of subpopulations of B lineage cells such as plasmablasts and memory B cells (Greenfield, Dandekar, 2019). One might also argue that an increased coverage of the B cell repertoires would have detected a higher number of non-frequent B cell clones in CSF and blood. This could, for instance, have yielded more matching CDR3 peptides and IGHV transcripts detected at both time points (Table 3). Although increased coverage is not possible in the CSF since low cell numbers is the main limitation in this compartment, deeper sequencing would have been doable in blood. Finally, PCR and sequencing errors are inherent in highthroughput immunosequencing and are often impossible to discern from somatic mutations (Lossius et al., 2016). In several instances, however, we detected mutated IgG from different members of the same lineage trees by mass spectrometry, strongly indicating that these variations were true somatic mutations. 
In conclusion, we detected a strong persistence of oligoclonal IgG in two MS patients, despite immunomodulatory treatment, and demonstrate that finite B cell samples only partly represent the cells producing oligoclonal IgG. Focusing on persisting IgG-producing B cell clones may be a strategy to pinpoint pathologically relevant B lineage cells in the search for target antigens.

\section{Financial support}

The study was supported by grants from the South-Eastern Norway Regional Health Authority (2011113 and 2016079).

\section{Acknowledgements}

We express our sincere gratitude to the patients who participated in the study and underwent a second lumbar puncture. We wish to thank Dr. Ramit Mehr, who kindly provided us the IgTree software.

\section{Disclosure of conflict of interest}

The authors declare no potential conflicting interests.

\section{Author Contributions}

Study concept and design: A.TB., J.N.J., T.H., V.G., M.S., G.A.S., F.V., A.L.; data acquisition and analysis: A.TB. J.N.J., V.G., M.S., G.A.S., A.L.; drafting the manuscript and/or images: A.TB., J.N.J., V.G., T.H., F.V., A.L. 


\section{References}

Alamyar E, Duroux P, Lefranc MP, Giudicelli V. IMGT((R)) tools for the nucleotide analysis of immunoglobulin (IG) and T cell receptor (TR) V-(D)-J repertoires, polymorphisms, and IG mutations: IMGT/V-QUEST and IMGT/HighV-QUEST for NGS. Methods Mol. Biol. 2012;882:569-604.

Axelsson M, Mattsson N, Malmestrom C, Zetterberg H, Lycke J. The influence of disease duration, clinical course, and immunosuppressive therapy on the synthesis of intrathecal oligoclonal IgG bands in multiple sclerosis. J. Neuroimmunol. 2013;264:100-5.

Bankoti J, Apeltsin L, Hauser SL, Allen S, Albertolle ME, Witkowska HE, et al. In multiple sclerosis, oligoclonal bands connect to peripheral B-cell responses. Ann. Neurol. $2014 ; 75: 266-76$.

Barak M, Zuckerman NS, Edelman H, Unger R, Mehr R. IgTree: creating Immunoglobulin variable region gene lineage trees. J. Immunol. Methods. 2008;338:67-74.

Beltran E, Obermeier B, Moser M, Coret F, Simo-Castello M, Bosca I, et al. Intrathecal somatic hypermutation of IgM in multiple sclerosis and neuroinflammation. Brain. 2014;137:2703-14.

Blauth K, Soltys J, Matschulat A, Reiter CR, Ritchie A, Baird NL, et al. Antibodies produced by clonally expanded plasma cells in multiple sclerosis cerebrospinal fluid cause demyelination of spinal cord explants. Acta Neuropathol. 2015;130:765-81.

Brandle SM, Obermeier B, Senel M, Bruder J, Mentele R, Khademi M, et al. Distinct oligoclonal band antibodies in multiple sclerosis recognize ubiquitous self-proteins. Proc. Natl. Acad. Sci. U. S. A. 2016;113:7864-9. 
Cameron EM, Spencer S, Lazarini J, Harp CT, Ward ES, Burgoon M, et al. Potential of a unique antibody gene signature to predict conversion to clinically definite multiple sclerosis. J. Neuroimmunol. 2009;213:123-30.

Cepok S, Rosche B, Grummel V, Vogel F, Zhou D, Sayn J, et al. Short-lived plasma blasts are the main B cell effector subset during the course of multiple sclerosis. Brain. 2005;128:1667-76.

Colombo M, Dono M, Gazzola P, Chiorazzi N, Mancardi G, Ferrarini M. Maintenance of B lymphocyte-related clones in the cerebrospinal fluid of multiple sclerosis patients. Eur. J. Immunol. 2003;33:3433-8.

Cox J, Mann M. MaxQuant enables high peptide identification rates, individualized p.p.b.range mass accuracies and proteome-wide protein quantification. Nat. Biotechnol. 2008;26:1367-72.

Dobson R, Ramagopalan S, Davis A, Giovannoni G. Cerebrospinal fluid oligoclonal bands in multiple sclerosis and clinically isolated syndromes: a meta-analysis of prevalence, prognosis and effect of latitude. J. Neurol. Neurosurg. Psychiatry. 2013;84:909-14.

Dyballa N, Metzger S. Fast and sensitive colloidal coomassie G-250 staining for proteins in polyacrylamide gels. J. Vis. Exp. 2009.

Greenfield AL, Dandekar R, Ramesh A, Eggers EL, Wu H, Laurent S, et al. Longitudinally persistent cerebrospinal fluid B cells can resist treatment in multiple sclerosis. $\mathrm{JCI}$ Insight. 2019;4.

Greiff V, Menzel U, Miho E, Weber C, Riedel R, Cook S, et al. Systems Analysis Reveals High Genetic and Antigen-Driven Predetermination of Antibody Repertoires throughout B Cell Development. Cell Rep. 2017;19:1467-78. 
Greiff V, Miho E, Menzel U, Reddy ST. Bioinformatic and Statistical Analysis of Adaptive Immune Repertoires. Trends Immunol. 2015;36:738-49.

Hoglund RA, Lossius A, Johansen JN, Homan J, Benth JS, Robins H, et al. In Silico Prediction Analysis of Idiotope-Driven T-B Cell Collaboration in Multiple Sclerosis. Front Immunol. 2017;8:1255.

Johansen JN, Vartdal F, Desmarais C, Tutturen AE, de Souza GA, Lossius A, et al. Intrathecal BCR transcriptome in multiple sclerosis versus other neuroinflammation: Equally diverse and compartmentalized, but more mutated, biased and overlapping with the proteome. Clin. Immunol. 2015;160:211-25.

Joseph FG, Hirst CL, Pickersgill TP, Ben-Shlomo Y, Robertson NP, Scolding NJ. CSF oligoclonal band status informs prognosis in multiple sclerosis: a case control study of 100 patients. J. Neurol. Neurosurg. Psychiatry. 2009;80:292-6.

Kabat EA, Glusman M, Knaub V. Quantitative estimation of the albumin and gamma globulin in normal and pathologic cerebrospinal fluid by immunochemical methods. Am. J. Med. 1948;4:653-62.

Larimore K, McCormick MW, Robins HS, Greenberg PD. Shaping of human germline IgH repertoires revealed by deep sequencing. J. Immunol. 2012;189:3221-30.

Ligocki AJ, Rivas JR, Rounds WH, Guzman AA, Li M, Spadaro M, et al. A Distinct Class of Antibodies May Be an Indicator of Gray Matter Autoimmunity in Early and Established Relapsing Remitting Multiple Sclerosis Patients. ASN Neuro. 2015;7.

Lossius A, Johansen JN, Vartdal F, Holmoy T. High-throughput sequencing of immune repertoires in multiple sclerosis. Ann Clin Transl Neurol. 2016;3:295-306. 
Lossius A, Tomescu-Baciu A, Holmoy T, Vedeler CA, Rosjo E, Lorentzen AR, et al. Selective intrathecal enrichment of G1m1-positive B cells in multiple sclerosis. Ann Clin Transl Neurol. 2017;4:756-61.

Lovato L, Willis SN, Rodig SJ, Caron T, Almendinger SE, Howell OW, et al. Related B cell clones populate the meninges and parenchyma of patients with multiple sclerosis. Brain. 2011;134:534-41.

Mancuso R, Franciotta D, Rovaris M, Caputo D, Sala A, Hernis A, et al. Effects of natalizumab on oligoclonal bands in the cerebrospinal fluid of multiple sclerosis patients: a longitudinal study. Mult. Scler. 2014;20:1900-3.

Obermeier B, Lovato L, Mentele R, Bruck W, Forne I, Imhof A, et al. Related B cell clones that populate the CSF and CNS of patients with multiple sclerosis produce CSF immunoglobulin. J. Neuroimmunol. 2011;233:245-8.

Obermeier B, Mentele R, Malotka J, Kellermann J, Kumpfel T, Wekerle H, et al. Matching of oligoclonal immunoglobulin transcriptomes and proteomes of cerebrospinal fluid in multiple sclerosis. Nat. Med. 2008;14:688-93.

Owens GP, Winges KM, Ritchie AM, Edwards S, Burgoon MP, Lehnhoff L, et al. VH4 gene segments dominate the intrathecal humoral immune response in multiple sclerosis. J. Immunol. 2007;179:6343-51.

Polman CH, Reingold SC, Banwell B, Clanet M, Cohen JA, Filippi M, et al. Diagnostic criteria for multiple sclerosis: 2010 revisions to the McDonald criteria. Ann. Neurol. 2011;69:292-302

Rounds WH, Salinas EA, Wilks TB, 2nd, Levin MK, Ligocki AJ, lonete C, et al. MSPrecise: A molecular diagnostic test for multiple sclerosis using next generation sequencing. Gene. 2015;572:191-7. 
Skorstad G, Vandvik B, Vartdal F, Holmoy T. MS and clinically isolated syndromes: shared specificity but diverging clonal patterns of virus-specific IgG antibodies produced in vivo and by CSF B cells in vitro. Eur. J. Neurol. 2009;16:1124-9.

Stern JN, Yaari G, Vander Heiden JA, Church G, Donahue WF, Hintzen RQ, et al. B cells populating the multiple sclerosis brain mature in the draining cervical lymph nodes. Sci. Transl. Med. 2014;6:248ra107.

Thompson AJ, Banwell BL, Barkhof F, Carroll WM, Coetzee T, Comi G, et al. Diagnosis of multiple sclerosis: 2017 revisions of the McDonald criteria. Lancet Neurol. 2018;17:16273.

Tintore M, Rovira A, Rio J, Tur C, Pelayo R, Nos C, et al. Do oligoclonal bands add information to MRI in first attacks of multiple sclerosis? Neurology. 2008;70:1079-83.

von Budingen HC, Kuo TC, Sirota M, van Belle CJ, Apeltsin L, Glanville J, et al. B cell exchange across the blood-brain barrier in multiple sclerosis. J. Clin. Invest. 2012;122:4533-43.

Walsh MJ, Tourtellotte WW. Temporal invariance and clonal uniformity of brain and cerebrospinal IgG, IgA, and IgM in multiple sclerosis. J. Exp. Med. 1986;163:41-53. 
Table 1. Patient characteristics and CSF parameters at the two time points.

\begin{tabular}{|c|c|c|c|c|c|c|c|c|c|c|c|c|}
\hline \multirow[t]{2}{*}{ ID } & \multirow{2}{*}{$\begin{array}{l}\text { Age } \\
\text { (years) }\end{array}$} & \multirow[t]{2}{*}{ Gender } & \multirow{2}{*}{$\begin{array}{l}\text { Disease } \\
\text { duration } \\
\text { (months) }\end{array}$} & \multirow{2}{*}{$\begin{array}{l}\text { Treatment between } \\
\text { sample collections }\end{array}$} & \multicolumn{4}{|c|}{$\mathrm{T}_{1}$} & \multicolumn{4}{|c|}{$T_{2}$} \\
\hline & & & & & EDSS & $\mathrm{OCB}$ & $\begin{array}{c}\text { IgG } \\
\text { index }\end{array}$ & $\begin{array}{l}\text { Albumin } \\
\text { ratio }\end{array}$ & EDSS & OCB & $\begin{array}{c}\text { IgG } \\
\text { index }\end{array}$ & $\begin{array}{l}\text { Albumin } \\
\text { ratio }\end{array}$ \\
\hline MS1 & 20 & $\mathrm{~F}$ & 12 & Natalizumab & 2.5 & + & 1.2 & 4.8 & 3.0 & + & 1.0 & 4.2 \\
\hline MS2 & 42 & $\mathrm{~F}$ & 64 & Interferon beta-1a & 1.0 & + & 0.94 & 5.5 & 3.5 & + & 1.0 & 3.6 \\
\hline
\end{tabular}


Table 2. Number of unique IGHV sequences and clustered non-redundant sequences.

\begin{tabular}{|c|c|c|c|c|c|c|c|c|}
\hline & \multicolumn{4}{|l|}{$\mathrm{T}_{1}$} & \multicolumn{4}{|l|}{$\mathrm{T}_{2}$} \\
\hline & \multicolumn{2}{|l|}{ CSF } & \multicolumn{2}{|l|}{ Blood } & \multicolumn{2}{|l|}{ CSF } & \multicolumn{2}{|l|}{ Blood } \\
\hline & Unique & $\begin{array}{l}\text { Clustered } \\
\text { non- } \\
\text { redundant }^{1}\end{array}$ & Unique & $\begin{array}{l}\text { Clustered } \\
\text { non- } \\
\text { redundant }^{1}\end{array}$ & Unique & $\begin{array}{l}\text { Clustered } \\
\text { non- } \\
\text { redundant }^{1}\end{array}$ & Unique & $\begin{array}{l}\text { Clustered } \\
\text { non- } \\
\text { redundant }^{1}\end{array}$ \\
\hline MS1 & 676 & 353 & 9213 & 3647 & 1856 & 390 & 6810 & 3562 \\
\hline MS2 & 1459 & 177 & 36088 & 22220 & 853 & 452 & 30339 & 21095 \\
\hline
\end{tabular}

${ }^{1}$ The sequences were clustered by identical V-gene, J-gene, CDR3 length, and a maximal edit distance

of 1 (see materials and methods). 
Table 3. Oligoclonal band CDR3 peptides.

\begin{tabular}{|c|c|c|c|c|c|c|}
\hline \multirow[t]{2}{*}{ ID } & \multicolumn{2}{|c|}{$\begin{array}{l}\text { Total CDR3 peptides } \\
\text { (matching IGHV } \\
\text { transcripts detected } \\
\text { at } \mathrm{T}_{1} \text { and/or } \mathrm{T}_{2} \text { ) }\end{array}$} & \multicolumn{2}{|c|}{$\begin{array}{l}\text { CDR3 peptides } \\
\text { detected at } T_{1} \text { and } T_{2}\end{array}$} & \multicolumn{2}{|c|}{$\begin{array}{l}\text { CDR3 peptides and } \\
\text { matching IGHV } \\
\text { transcripts detected } \\
\text { at } \mathrm{T}_{1} \text { and } \mathrm{T}_{2}\end{array}$} \\
\hline & CSF & Blood & CSF & Blood & CSF & Blood \\
\hline MS1 & 22 & 13 & 20 & 8 & 5 & 1 \\
\hline MS2 & 28 & 24 & 25 & 16 & 6 & 0 \\
\hline
\end{tabular}




\section{Figure legends}

Fig. 1. Identical and related B lineage cells are overlapping in space and time. (A) Venn diagrams visualizing the overlap of IGHV transcripts between CSF and blood at two time points, 18 months apart $\left(T_{1}\right.$ and $\left.T_{2}\right)$ in MS1 and MS2. The numbers given are unique IGHV sequences with clustered non-redundant sequences in parentheses. (B) Representative lineages trees from MS1 and MS2 comprising identical and related IGHV transcripts from CSF and blood at the two time points. Each node represents an IGHV sequence. Lines without denotation depict one nucleotide exchange between the connected nodes, " 2 " depict two, and so on. Germline (GL) nodes are on top of each tree. Blue nodes represent IGHV transcripts only detected in CSF, red nodes are transcripts found in CSF and blood, and white nodes are hypothetical nodes created by the IgTree software. Circles represent IGHV transcripts detected exclusively at $T_{1}$, triangles are transcripts only detected at $T_{2}$, and squares are sequences detected at both time points.

Fig. 2. Oligoclonal band CDR3 peptides show a strong qualitative and quantitative persistence in the CSF. The graphs show the abundance of CDR3 peptides based on LC-MS intensities obtained by MaxQuant. Black and red circles represent peptides mapping to transcripts from CSF and blood, respectively.

Fig, 3. Identical and related B lineage cells matching intrathecally produced IgG are overlapping in space and time in MS1. (A) The figure shows immobilized pH gradient (IPG) strips with isoelectric focused CSF and serum from two time points, 18 months apart ( $T_{1}$ and $T_{2}$ ) in MS1. After processing and staining the strips as described in Materials and Methods, 
the areas indicated by brackets were excised and analyzed by mass spectrometry. In addition, we cut out a part of the strip without any visible bands as a negative control. (B) Lineage trees and matching CDR3 peptides from MS1. The nodes, lines and numbers depict the IGHV sequences and the number of nucleotide exchange between them as described in Fig. 1. Blue nodes represent IGHV transcripts only detected in CSF, red nodes are transcripts exclusively detected in blood, yellow nodes represent transcripts detected in CSF and blood, and white nodes are hypothetical sequences. Circles depict sequences only detected at $T_{1}$, triangles were exclusively detected at $T_{2}$, and squares represent sequences detected at both $T_{1}$ and $T_{2}$. The letters in the nodes refers to the letters behind the aligned sequences, and the shaded areas of the trees and the aligned sequences are mass spectrometry CDR3 peptide hits. The graphs show the relative quantities of peptides detected in distinct oligoclonal bands (OCBs) at both time points based on label-free quantitation of mass spectrometry data in MaxQuant.

Fig. 4. Identical and related $B$ lineage cells matching intrathecally produced IgG are overlapping in space and time in MS2. (A, B) IGHV sequences and mass spectrometry data of oligoclonal bands (OCBs) were analyzed and visualized as described in Fig. 3. 
A

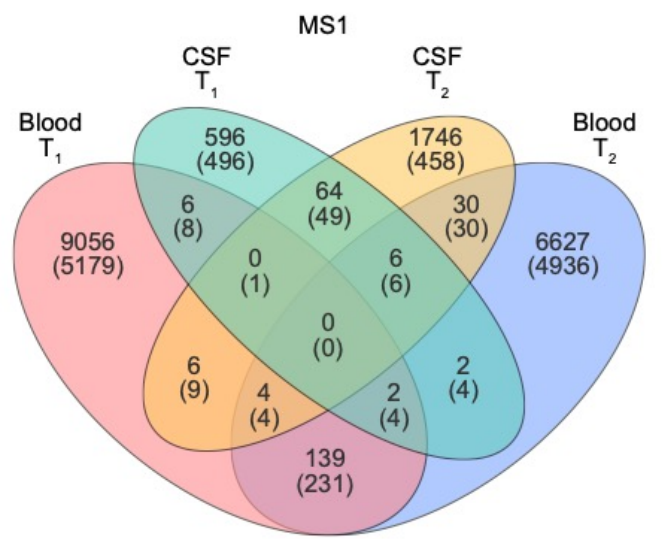

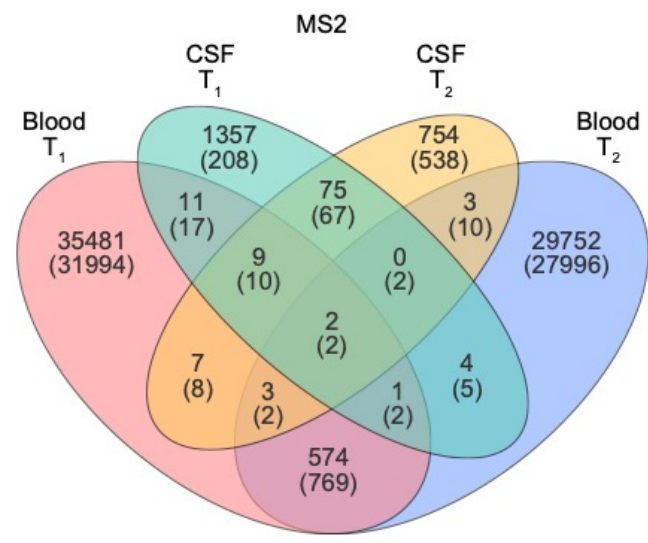

MS1

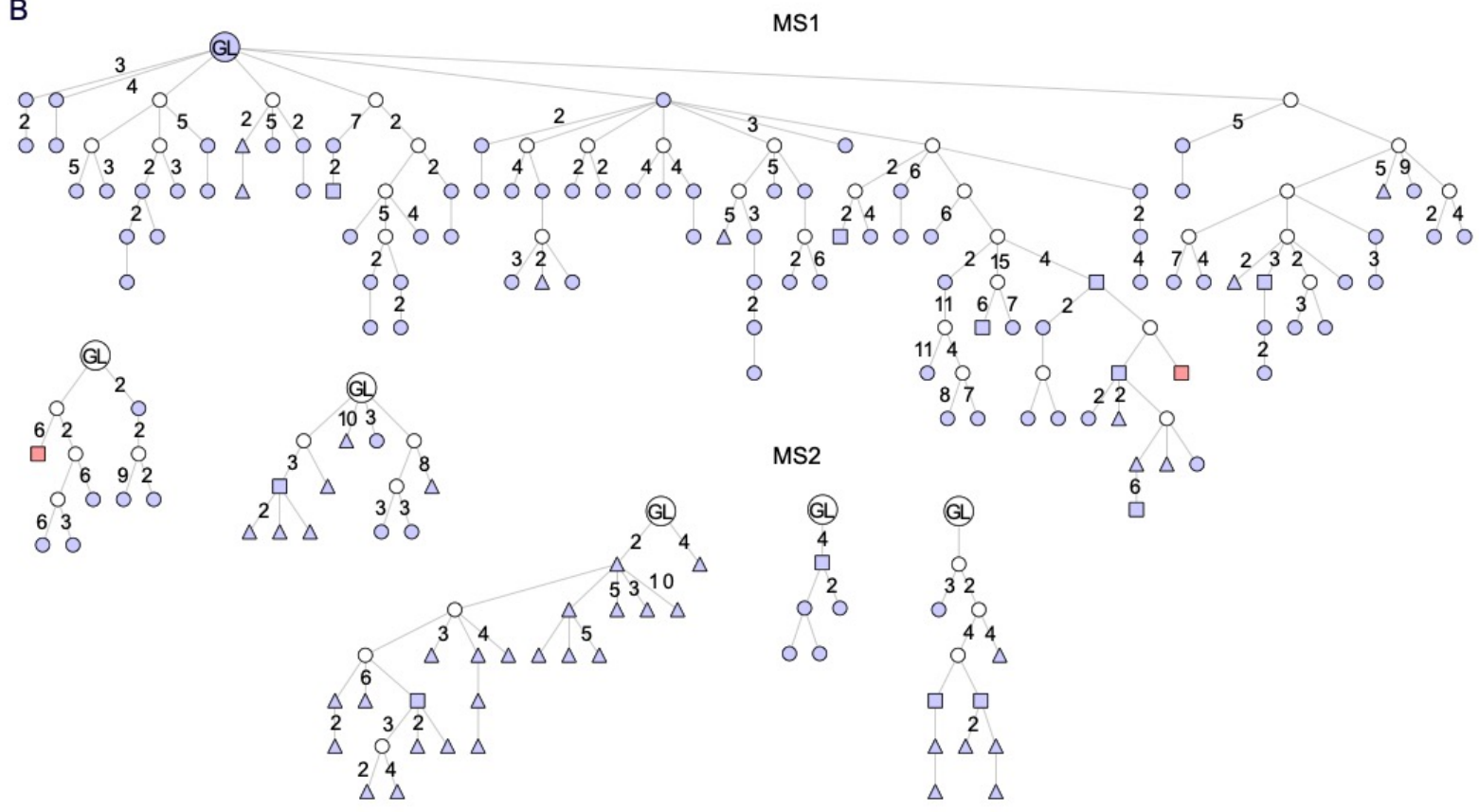

Figure 1 


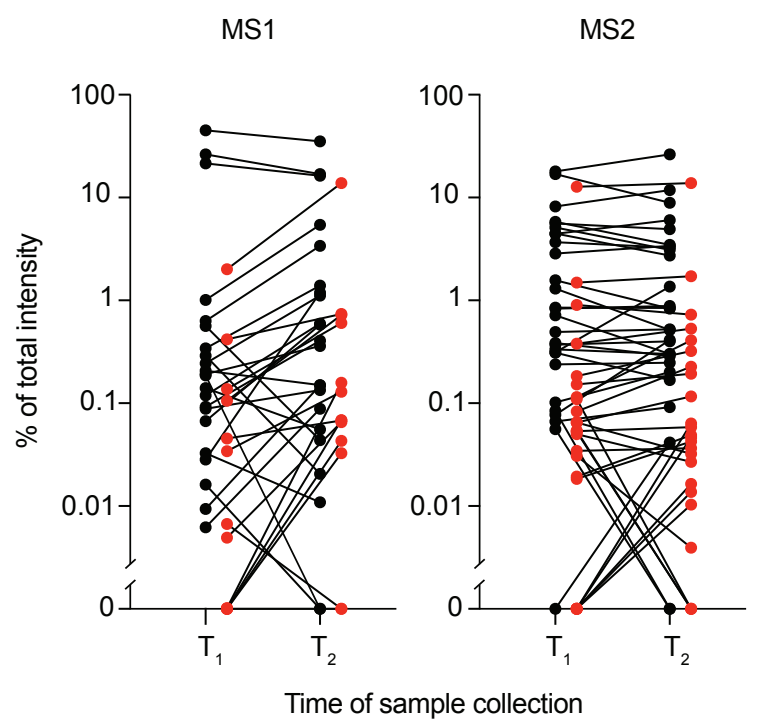

Figure 2 
A

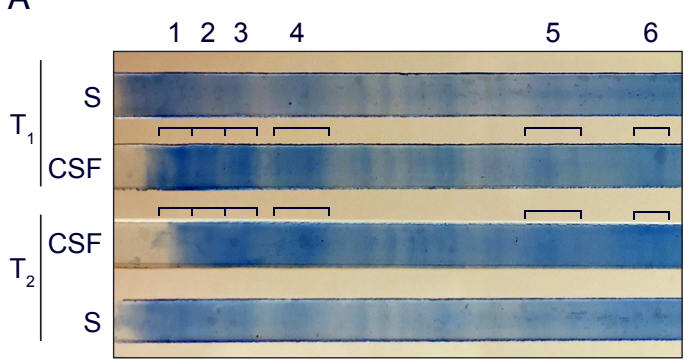

B

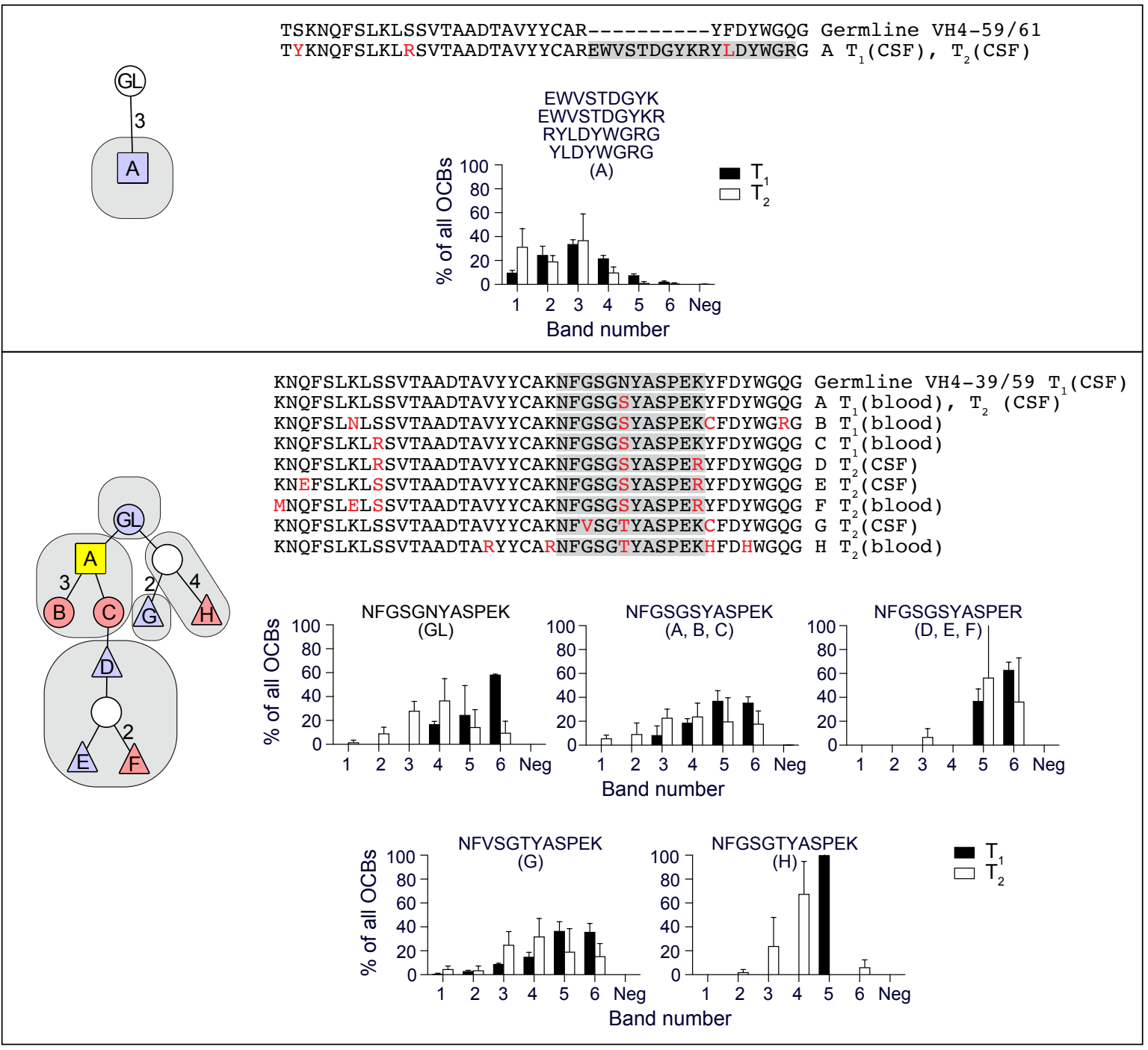

Figure 3 


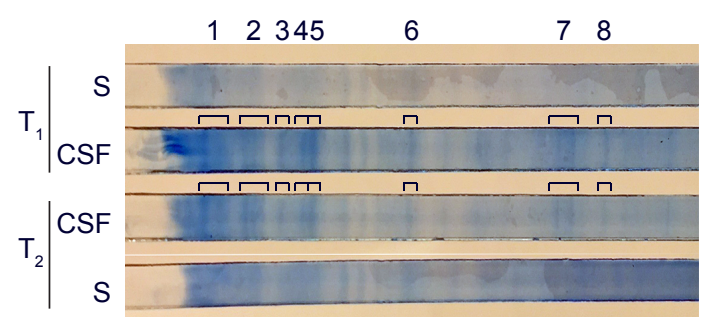

B

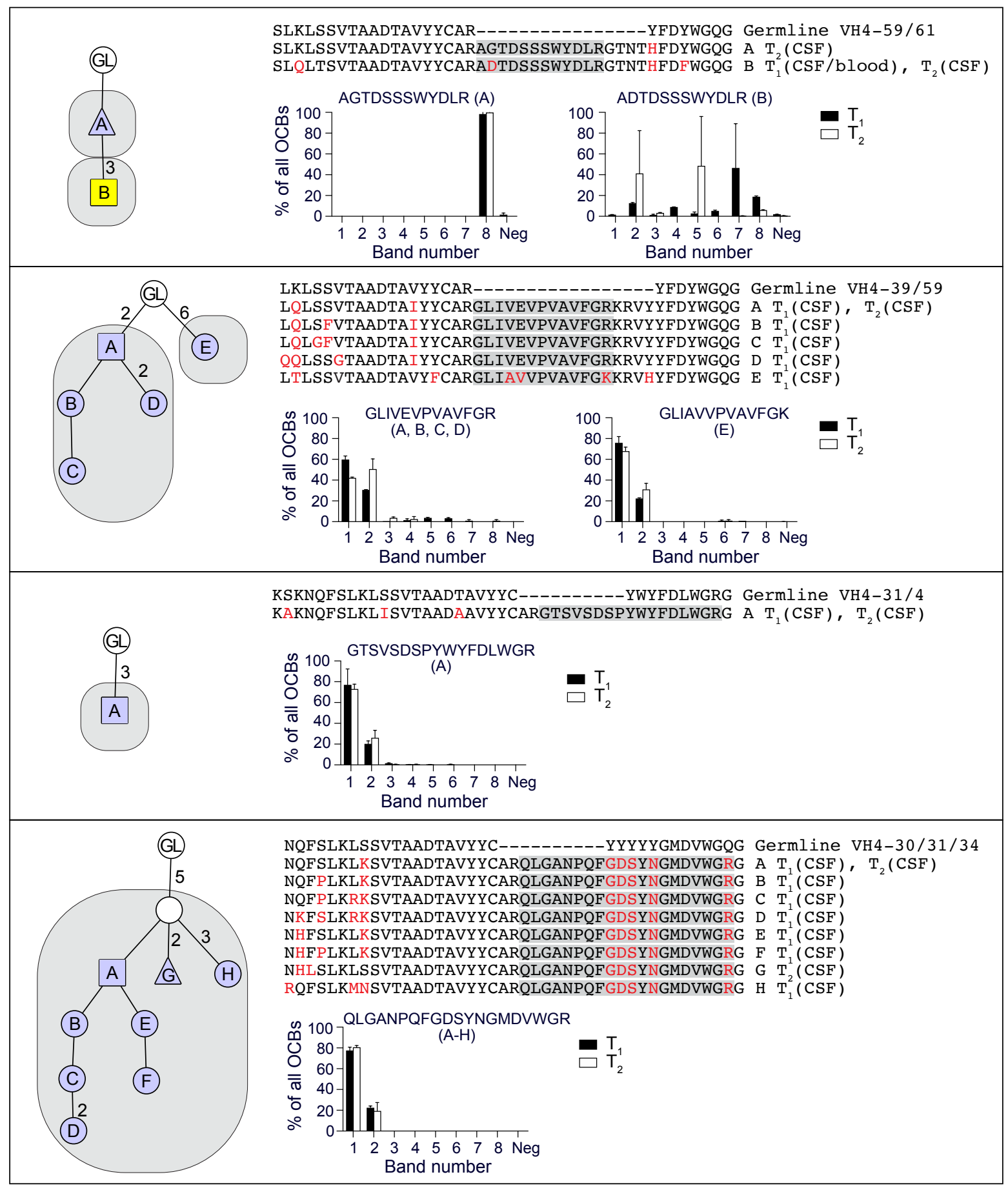

Figure 4 